Bull. Chem. Soc. Ethiop. 2018, 32(3), 491-500.

ISSN 1011-3924

(c) 2018 Chemical Society of Ethiopia and The Authors

Printed in Ethiopia

DOI: https://dx.doi.org/10.4314/bcse.v32i3.8

\title{
SYNTHESIS AND CRYSTALLOGRAPHIC CHARACTERIZATION OF NEW HETEROTRINUCLEAR OXO-CENTERED COMPLEX
}

\author{
Melika Eftekhar ${ }^{1 *}$, Haman Tavakkoli $^{2 *}$, Iman Khosravi $^{1}$ and Arezoo Ghaemi ${ }^{3}$ \\ ${ }^{1}$ Department of Chemistry, Qeshm Branch, Islamic Azad University, Qeshm, Iran \\ ${ }^{2}$ Young Researchers and Elite Club, Ahvaz Branch, Islamic Azad University, Ahvaz, Iran \\ ${ }^{3}$ Department of Chemistry, Ahvaz Branch, Islamic Azad University, Ahvaz, Iran
}

(Received February 15, 2018; Revised September 17, 2018; Accepted October 2, 2018)

\begin{abstract}
New oxo-centered trinuclear mixed-metal complex, of $\left[\mathrm{Fe}_{2} \mathrm{ZnO}\left(\mathrm{CHCl}_{2} \mathrm{CO}_{2}\right)_{6}\left(\mathrm{CHCl}_{2} \mathrm{CO}_{2}\right)_{3}\right] \cdot \mathrm{NO}_{3}$ was synthesized by the direct reaction between metal nitrates and dichloroacetic acid. These compounds have a typical $\mu_{3}$-oxo trinuclear structure: (a) three metal atoms are situated in the apexes of the equilateral triangle; (b) $\mu_{3}$-oxygen atom and six dichloroacetate ligands fulfil the bridge functions and (c) the monodentate $\mathrm{CHCl}_{2} \mathrm{CO}_{2}$ ligands complete the octahedral geometry of the metal ions. This complex were characterized by elemental analyses (CHN), atomic absorption spectroscopy and spectral (IR, electronic) studies. This is new types of oxobridged mixed-metal complex in which the carboxylate ligand is dichloroacetic acid. The UV spectra of the complex exhibited strong bands in the region 213 and $257 \mathrm{~nm}$ which are related to the $\left(\pi \rightarrow \pi^{*}\right)$ and $\left(\mathrm{n} \rightarrow \pi^{*}\right)$ transitions of the $\mathrm{CHCl}_{2} \mathrm{CO}_{2}$ ligands, respectively. The IR spectra of this compound showed two strong stretching vibrations bands, indicating a bridging coordination mode of the carboxylic group by presence of $v_{\text {asym }}\left(\mathrm{M}_{2} \mathrm{M}^{\prime} \mathrm{O}\right)$ vibrations of the ligand in the infrared spectra.
\end{abstract}

KEY WORDS: Oxo-centered, Trinuclear complexes, Carboxylic ligand, Crystallographic data, IR spectra

\section{INTRODUCTION}

Transition-metal carboxylate chemistry has played a key role in the conceptual development of modern inorganic chemistry [1]. The current interest in the trinuclear, oxo-centered metal carboxylate assemblies of the general composition $\left[\mathrm{M}_{3} \mathrm{O}(\mathrm{OOCR})_{6} \mathrm{~L}_{3}\right]^{+}$(where $\mathrm{M}=$ trivalent 3-d metal, $\mathrm{RCOO}=$ carboxylic acid $\left(\mathrm{R}=\mathrm{CH}_{3}, \mathrm{Ph}\right.$, etc $) \mathrm{L}=$ monodentate ligand $)$ is due to these complexes have served as important models to test theories of magnetic and electronic coupling between metal ions [2, 3]. They are particularly valuable as frame works for systematically studying metal-metal interactions in clusters and constitute an important class of compounds in transition metal chemistry. They have been characterized with a wide variety of first-row and heavier transition metals, with mixed-metal [4] and mixed-valency combinations [5].

Electron transfer interactions, and subtle distortions from regular structures, can be detected by their effects on molecular vibrations. These are valuable precursors for the synthesis of higher nuclearity clusters exhibiting interesting magnetic properties. Surprisingly, little attention has been paid to the consideration of substitution properties, with only a few reports of comparative studies regarding the redox properties when the terminal ligand $\mathrm{L}$ changes. There is interest in establishing how substitution in the carboxylate bridge affects the liability of the terminal ligand and the redox potential of the metal centers. These carboxylate complexes are of additional interest when the carboxylate is unsaturated, because there is a potential scope for further polymerization in the solid state by cross-linking of the substituents [6,7]. Trinuclear $\mu_{3}$,-oxo-bridged iron carboxylate complexes have been studied in very detail $[8,9]$, whereas analogous mixed-valence manganese-carboxylate complexes have been the object of only limited investigation to date. Each carboxylate anion spans two metal centers at the periphery of

*Corresponding author. E-mail: Melika_eftekhar@yahoo.com

This work is licensed under the Creative Commons Attribution 4.0 International License 
the $\left[\mathrm{M}_{3}\left(\mu_{3}-\mathrm{O}\right)\right]^{6+}$ core, while the neutral monodentate ligands occupy the remaining coordination sites on each metal center, and as a result the coordination around the metal center is approximately octahedral (Figure 1).

In previous studies, we reported fabrication of some trinuclear oxo-centered complexes with saturated and unsaturated carboxylate ligands [10-14]. In this paper, the syntheses and characterization of mixed-valence and mixed-metal clusters are reported. These are, however, limited to clusters coordinated by relatively small organic ligands.

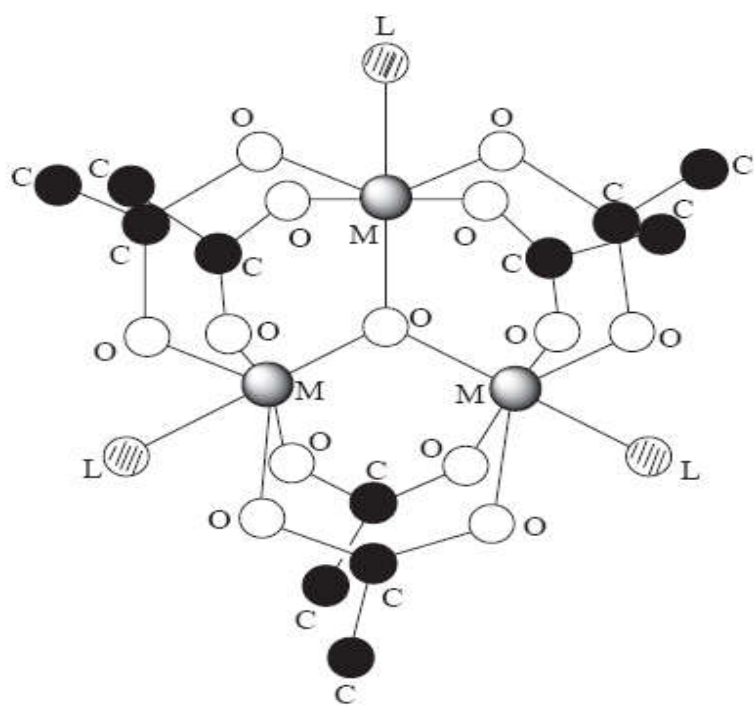

Figure 1. Schematic representation of the oxo-centered trinuclear clusters structure $\left[\mathrm{M}_{3} \mathrm{O}(\mathrm{RCOO})_{6}(\mathrm{~L})_{3}\right]^{\mathrm{z}}$.

\section{EXPERIMENTAL}

\section{Materials}

The $\mathrm{C}, \mathrm{H}$ and $\mathrm{N}$ analyses were realized on a Thermo Finnigan Flash model EA1112 elemental analyzer. The atomic absorption analyses were performed on a Shimadzu model AA-670 atomic absorption spectrometer. The IR spectra of $\mathrm{KBr}$ discs $\left(600-4000 \mathrm{~cm}^{-1}\right)$ were recorded on a Buck 500 spectrometer. The electronic spectra were registered in the range of $200-600 \mathrm{~nm}$ on a Perkin-Elmer 1600 spectrometer.

Preparation of $\left[\mathrm{Fe}_{2} \mathrm{ZnO}\left(\mathrm{CHCl}_{2} \mathrm{CO}_{2}\right)_{6}\left(\mathrm{CHCl}_{2} \mathrm{CO}_{2}\right)_{3}\right] \cdot \mathrm{NO}_{3}$

A mixture of $\mathrm{Fe}\left(\mathrm{NO}_{3}\right)_{3} .9 \mathrm{H}_{2} \mathrm{O}(1.08 \mathrm{~g}, 2.68 \mathrm{mmol})$ and $\mathrm{Zn}\left(\mathrm{NO}_{3}\right)_{2} .4 \mathrm{H}_{2} \mathrm{O}(0.34 \mathrm{~g}, 1.34 \mathrm{mmol})$ was dissolved in $25 \mathrm{~mL}$ deionized water and was refluxed for $10 \mathrm{~min}$. Then, $\mathrm{NaCHCl}_{2} \mathrm{CO}_{2}(2.22 \mathrm{~g}$, $12 \mathrm{mmol}$ ) was added and the reflux continued for $5 \mathrm{~h}$. The resulting brown solution was allowed to cool and stored for 2 days at $20{ }^{\circ} \mathrm{C}$. The black crystals were filtered off, washed copiously with $\mathrm{Et}_{2} \mathrm{O}$ and dried in vacuum. (Yield: 85\%), m.p.: $275{ }^{\circ} \mathrm{C}$, anal. calc. for $\mathrm{C}_{12} \mathrm{H}_{12} \mathrm{Cl}_{12} \mathrm{Fe}_{2} \mathrm{ZnNO}_{22}$ : C, 10.89; H, 0.45; N, 1.06; Fe, 8.47; Zn, 4.16\%. Found: $\mathrm{C}, 10.64 ; \mathrm{H}$, $0.62 ; \mathrm{N}, 1.14 ; \mathrm{Fe}, 8.85 ; \mathrm{Zn}, 4.39 \%$. 


\section{RESULTS AND DISCUSSION}

\section{Description of the structure}

The asymmetric unit of synthesized complex comprises a single complex anion (total charge 3-: two $\mathrm{Fe}^{3+}$ and $\mathrm{a} \mathrm{Zn}^{2+}$ atom, an oxide dianion and nine dichloroacetate anions) and three pyridinium cations. Metal coordination spheres are slightly deformed octahedra (Table 1); oxygens from four bridging dichloroacetate (DCA) moieties form the equatorial plane, while the axial ligands are a terminal monodentate DCA and the central oxide dianion (Figure 2). The oxide dianion (O19) is coordinated by three metal atoms in a nearly perfect planar arrangement (within experimental error, Figure 2); bond angles are $120.9(2)^{\circ}(\mathrm{Fe} 1-\mathrm{O} 19-\mathrm{Fe} 2), 119.5(2)^{\circ}(\mathrm{Fe} 1-$ $\mathrm{O} 19-\mathrm{Zn} 1)$ and $119.5(2)^{\circ}(\mathrm{Fe} 2-\mathrm{O} 19-\mathrm{Zn} 1)$. There are six bridging bidentate and three terminal monodentate DCA moieties, and the entire complex trianion has an approximate molecular symmetry Cs (Figure 3).

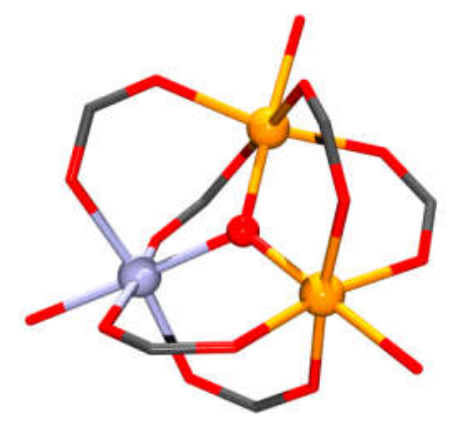

Figure 2. Coordinations of metal atoms and the central oxide dianion in $\left[\mathrm{Fe}_{2} \mathrm{ZnO}\left(\mathrm{CHCl}_{2} \mathrm{CO}_{2}\right)_{6}\left(\mathrm{CHCl}_{2} \mathrm{CO}_{2}\right)_{3}\right]$ Dichloromethyl moieties have been omitted for clarity.

Table 1. Geometric parameters of metal coordination spheres.

\begin{tabular}{|l|l|l|l|l|l|}
\hline \multicolumn{2}{|c|}{ Zn1 } & \multicolumn{2}{c|}{} \\
\hline Zn1-O19 & $1.950(4)$ & Fe1-O19 & $1.921(4)$ & Fe2-O19 & $1.906(3)$ \\
\hline Zn1-O4 & $2.056(4)$ & Fe1-O6 & $2.027(4)$ & Fe2-O10 & $2.034(4)$ \\
\hline Zn1-O1 & $2.065(4)$ & Fe1-O5 & $2.045(4)$ & Fe2-O11 & $2.043(4)$ \\
\hline Zn1-O3 & $2.068(4)$ & Fe1-O7 & $2.045(4)$ & Fe2-O12 & $2.048(5)$ \\
\hline Zn1-O2 & $2.082(4)$ & Fe1-O9 & $2.055(4)$ & Fe2-O8 & $2.069(4)$ \\
\hline Zn1-O13 & $2.082(4)$ & Fe1-O15 & $2.093(4)$ & Fe2-O17 & $2.084(3)$ \\
\hline O19-Zn1-O4 & $94.58(16)$ & O19-Fe1-O6 & $95.07(17)$ & O19-Fe2-O10 & $92.59(16)$ \\
\hline O19-Zn1-O1 & $93.86(16)$ & O19-Fe1-O5 & $94.04(17)$ & O19-Fe2-O11 & $95.22(16)$ \\
\hline O19-Zn1-O3 & $97.13(17)$ & O19-Fe1-O7 & $97.73(17)$ & O19-Fe2-O12 & $96.73(16)$ \\
\hline O19-Zn1-O2 & $92.08(16)$ & O19-Fe1-O9 & $93.10(17)$ & O19-Fe2-O8 & $96.30(16)$ \\
\hline O19-Zn1-O13 & $178.28(16)$ & O19-Fe1-O15 & $178.80(16)$ & O19-Fe2-O17 & $177.58(19)$ \\
\hline O4-Zn1-O1 & $171.26(16)$ & O6-Fe1-O5 & $92.53(16)$ & O10-Fe2-O11 & $171.78(14)$ \\
\hline O4-Zn1-O3 & $85.09(16)$ & O6-Fe1-O7 & $167.20(18)$ & O10-Fe2-O12 & $89.81(18)$ \\
\hline O4-Zn1-O2 & $95.62(17)$ & O6-Fe1-O9 & $87.51(15)$ & O10-Fe2-O8 & $92.14(17)$ \\
\hline O4-Zn1-O13 & $83.71(16)$ & O6-Fe1-O15 & $86.06(16)$ & O10-Fe2-O17 & $86.09(15)$ \\
\hline O1-Zn1-O3 & $91.62(15)$ & O5-Fe1-O7 & $86.87(16)$ & O11-Fe2-O12 & $91.82(18)$ \\
\hline O1-Zn1-O2 & $86.34(15)$ & O5-Fe1-O9 & $172.82(18)$ & O11-Fe2-O8 & $84.47(17)$ \\
\hline O1-Zn1-O13 & $87.84(16)$ & O5-Fe1-O15 & $85.46(16)$ & O11-Fe2-O17 & $86.01(15)$ \\
\hline O3-Zn1-O2 & $170.69(16)$ & O7-Fe1-O9 & $91.50(15)$ & O12-Fe2-O8 & $166.72(14)$ \\
\hline O3-Zn1-O13 & $82.55(16)$ & O7-Fe1-O15 & $81.15(16)$ & O12-Fe2-O17 & $85.31(15)$ \\
\hline O2-Zn1-O13 & $88.29(16)$ & O9-Fe1-O15 & $87.39(16)$ & O8-Fe2-O17 & $81.72(15)$ \\
\hline
\end{tabular}


The pyridinium cations are tethered to terminal monodentate DCA moieties through $\mathrm{N}-\mathrm{H} \cdots \mathrm{O}$ hydrogen bonds; between such units exist only dispersion interactions.

The single-crystal diffraction measurement was performed on a Siemens SMART three axis goniometer with APEX II area detector system equipped with a liquid-nitrogen cooling device. Bruker AXS APEX 2 Vers. 2.0-2 2006 software was used for data reduction and multi-scan absorption correction. The structure was solved and refined using SHELXTL program implemented in the APEX 2 software; full-matrix least-squares refinement vs. F2 was used. All non-hydrogen atoms were refined anisotropically, and hydrogen atoms were treated as riding model on idealized geometries with the 1.2 fold isotropic displacement parameters of the equivalent Uij of the corresponding carbon atom. Dichloromethyl groups (atoms C72, Cl5, and Cl6) were disordered over two sites with SOF 0.63; $\mathrm{Cl} 7$ and $\mathrm{Cl} 8$ were disordered over two sites with respective SOFs 0.91 and 0.66 . Crystallographic, measurement and refinement data are shown in Table 2.
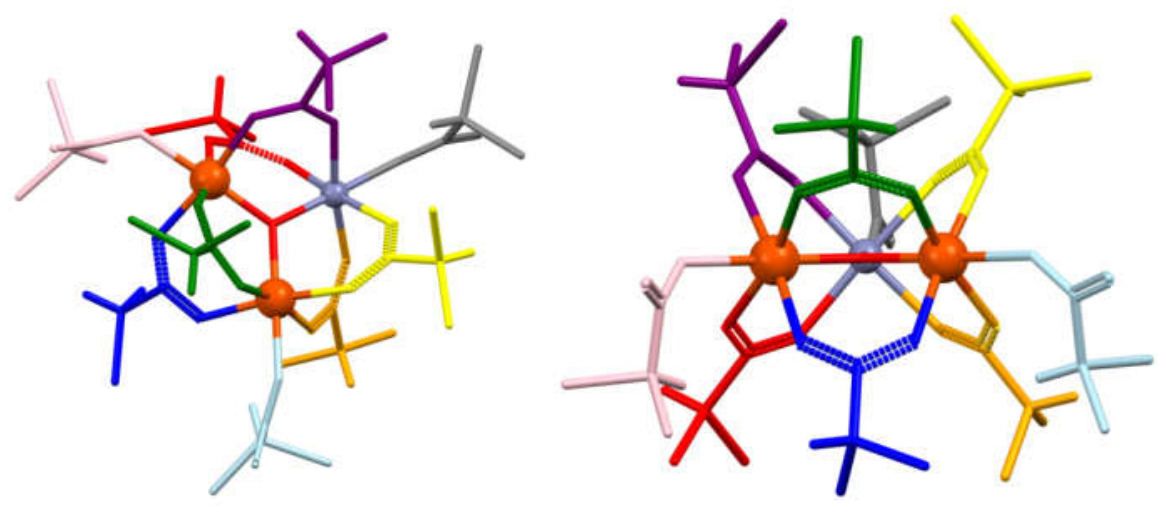

Figure 3. Molecular structure of the complex anion of $\left[\mathrm{Fe}_{2} \mathrm{ZnO}\left(\mathrm{CHCl}_{2} \mathrm{CO}_{2}\right)_{6}\left(\mathrm{CHCl}_{2} \mathrm{CO}_{2}\right)_{3}\right]$ a) the least-overlap view showing three metal cations bridged by six DCA moieties and an oxide dianion and b) view showing its pseudo- $C_{2}$ molecular symmetry. Symmetryinequivalent dichloroacetate ligands are colour-coded; Fe atoms are shown as dark orange spheres and the $\mathrm{Zn}$ atom is shown as a blue-gray sphere.

Figure 4 shows an ORTEP projection of the complex molecule $\left[\mathrm{Fe}_{2} \mathrm{ZnO}\left(\mathrm{CHCl}_{2} \mathrm{CO}_{2}\right)_{6}\left(\mathrm{CHCl}_{2} \mathrm{CO}_{2}\right)_{3}\right] . \mathrm{NO}_{3}$ that crystallize isotopically in the triclinic space group type $\mathrm{P} 1$. The crystal structure analysis reveals that this material consists of two iron(III) and one zinc(II) ions are situated at the apexes of the isosceles triangle $(\mathrm{Zn}(1)-\mathrm{Fe}(1) 3.272(1)$, $\mathrm{Zn}(1)-\mathrm{Fe}(2) 3.274(2), \mathrm{Fe}(1)-\mathrm{Fe}(2) 3.266(1) \AA$ ) and a triply bridging oxygen atom in its center. Two $\mathrm{CHCl}_{2}$-COO- anions, with syn-syn configuration, which bridge the same pair of metal atoms lie on the opposite sides of the $\mathrm{Fe}_{2} \mathrm{ZnO}$ plane. Crystal data, and selected bonds lengths and angles are summarized in Table 1. A careful inspection of the electron-density distribution, bond lengths, and atomic vibrational parameters at the three metal sites do not indicate any definite evidence for position of the $\mathrm{Zn}$ (II) ion in a particular metal site, even though atom $\mathrm{Zn}$ has slightly longer $\mathrm{M}-\mu_{3}-\mathrm{O}$ bond (mean $1.891 \AA$ ) than those $\mathrm{Fe}(\mathrm{III})-\mu_{3}-\mathrm{O}$ (mean 1.875 ) which may indicate some preference for this location to be occupied by the larger $\mathrm{Zn}$ (II) ion, the difference of $0.016 \AA$ is significantly less than would be expected in a fully ordered structure: $\mathrm{Zn}(\mathrm{II})-\mu_{3}-\mathrm{O}$ bonds are typically $0.1 \AA$ longer than $\mathrm{Fe}(\mathrm{III})-\mu_{3}-\mathrm{O}$ bonds, and in the $\mathrm{Fe}(\mathrm{III})_{2} \mathrm{Zn}(\mathrm{II})$ complex [16] the M- $\mu_{3}-\mathrm{O}$ bond distances for the position occupied by the $\mathrm{Zn}(\mathrm{II})$ metal exceed with an average value of $0.2 \AA$, the corresponding distances for the iron(III) 
positions. Moreover, the three $\mathrm{M}-\mathrm{O}\left(\mathrm{CHCl}_{2} \mathrm{CO}_{2}\right)$ bonds in $\mathbf{1}$ are approximately equal (Table 1). On the balance of the evidence, we consider that each metal ions position in this compound is too small for the observed bond lengths and angles to be used in a consequential discussion of the individual metal coordination geometries.

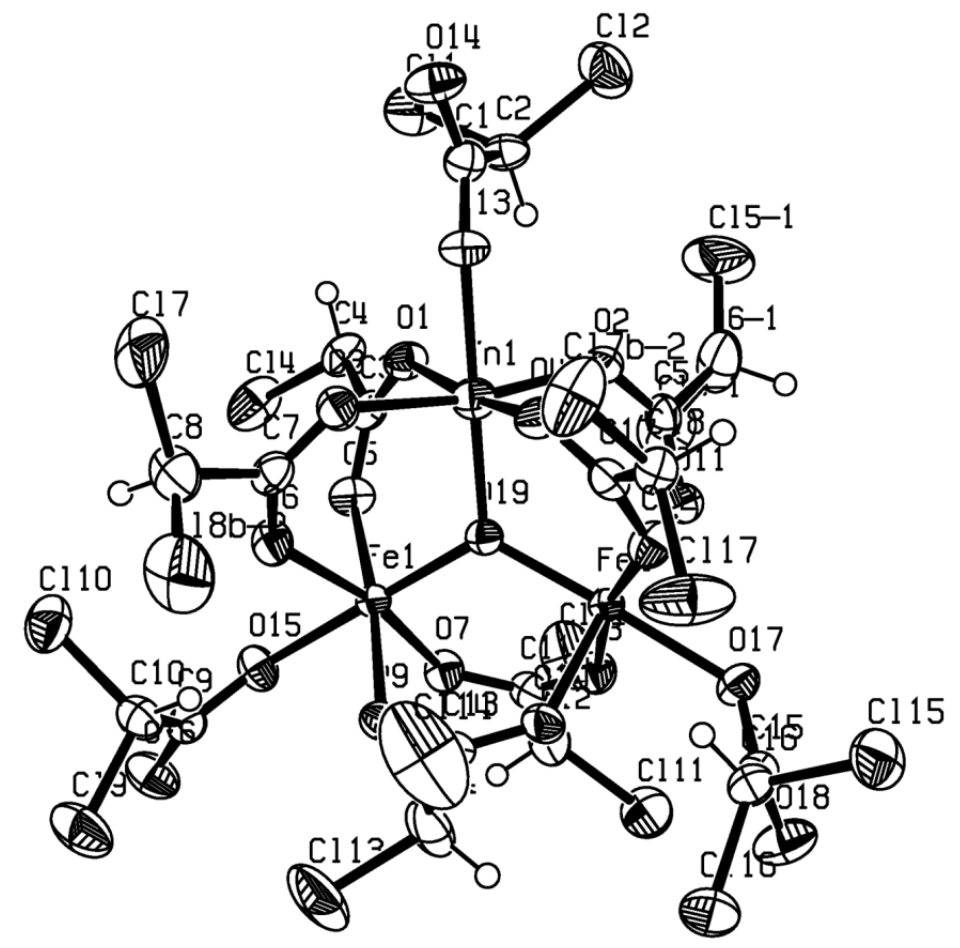

Figure 4. ORTEP-3 drawing of a molecule of $\left[\mathrm{Fe}_{2} \mathrm{ZnO}\left(\mathrm{CHCl}_{2} \mathrm{CO}_{2}\right)_{6}\left(\mathrm{CHCl}_{2} \mathrm{CO}_{2}\right)_{3}\right] \cdot \mathrm{NO}_{3}$. Only major component of the disorder is shown; displacement ellipsoids are drawn for the probability of $50 \%$ and hydrogen atoms are shown as spheres of arbitrary radii.

IR spectroscopy

For the mixed-metal complexes, it appears from the carboxylate stretching frequencies that all six ligands are approximately equivalent and they are best represented as bidentate bridges. For a new series of trinuclear mixed metal complexes, Cannon assigned the IR spectra and identified the vibrational modes of the central $\mathrm{M}_{3} \mathrm{O}$ core [17]. He found that the reduction in site geometry from $\mathrm{D}_{3} \mathrm{~h}$ to $\mathrm{C}_{2} \mathrm{v}$ lifted the degeneracy of the asymmetric $\mathrm{M}_{3} \mathrm{O}$ stretches and two bands were seen.

Buildings of metal carboxylates according to the type of metal-ligand interaction are presented in Figure 5. The major difference in the IR spectra between monodentate (type II) and bidentate bridging (existing in oxo-centered complexes) (type IV) groups, is that the $\mathrm{CO}_{\text {asym }}$ is generally smaller for the latter. Generally, a common trend for both stretching frequencies and/or band separation values can be outlined as: uncoordinated acid $>$ unidentate coordination $>$ bidentate (bridging $>$ chelating) coordination. This spectrum indicate a single pair of 
carboxylate stretching vibrations at 1615 and $1430 \mathrm{~cm}^{-1}$ for assigned to $v_{\text {asym }}(\mathrm{COO})$ and $v_{\text {sym }}(\mathrm{COO})$, respectively. Since the difference $\left[\Delta v=v_{\text {asym }}\left(\mathrm{CO}_{2}\right)-v_{\text {sym }}\left(\mathrm{CO}_{2}\right)\right]$ is $185 \mathrm{~cm}^{-1}$ for title complex and this value is less than the $\Delta v$ value for $\mathrm{NaO}_{2} \mathrm{C}_{2} \mathrm{HCl}_{2}$ (type I) of ( $\left.200 \mathrm{~cm}-1\right)$, we expect bidentate bridging coordination of carboxylates in this compound [18]. The IR spectrum of this complex is shown in Figure 6 that indicates the presence of carboxylate ligands and $\left\{\mathrm{M}_{2} \mathrm{MO}\right\}$ groups. The observed vibrational frequencies $v_{\text {asym }}(\mathrm{COO})$ and $v_{\text {sym }}(\mathrm{COO})$ for the carboxylate ligand support the presence of bridging coordinated carboxylates in all the complexes. For identification of the metal-oxygen bonds of $\mathrm{M}_{3} \mathrm{O}$ group, IR spectra in the range of $800-400 \mathrm{~cm}^{-1}$ were used [19]. The band observed for asymmetric vibration associated with the $\mathrm{M}_{2} \mathrm{M}$ 'O unit splits into two components, $A_{1}$ and $B_{2}$ [20]. This spectrum shows the characteristic bands for the valence oscillations $v_{\text {as }}\left(\mathrm{Fe}_{2} \mathrm{ZnO}\right)$ in the region $680 \mathrm{~cm}^{-1}\left(\mathrm{~A}_{1}\right)$ and 450 $\mathrm{cm}^{-1}\left(\mathrm{~B}_{2}\right)$. All data of IR spectroscopy for this compound are given in Table 3 .

Table 2. Crystallorgraphic, measurement and structure refinement data.

\begin{tabular}{|c|c|}
\hline Empirical formula & $\mathrm{C}_{33} \mathrm{H}_{24} \mathrm{~N}_{3} \mathrm{Cl}_{18} \mathrm{Fe}_{2} \mathrm{O}_{19} \mathrm{Zn}$ \\
\hline $\mathrm{M}_{\mathrm{r}} / \mathrm{g} \mathrm{mol}^{-1}$ & 1581.72 \\
\hline$D_{\text {calc }} / \mathrm{g} \mathrm{cm}^{-3}$ & 1.842 \\
\hline$F(000)$ & 1566 \\
\hline$T / \mathrm{K}$ & $203(2)$ \\
\hline Crystal size / $\mathrm{mm}$ & $0.26 \times 0.21 \times 0.08$ \\
\hline Crystal colour & brown \\
\hline Crystal description & plate \\
\hline Wavelength & $0.71073 \AA$ \\
\hline Crystal system & triclinic \\
\hline Space group & $P \overline{1}$ \\
\hline$a / \AA$ & $12.0183(6)$ \\
\hline$b / \AA$ & $15.4721(7)$ \\
\hline$c / \AA$ & $17.3879(8)$ \\
\hline$\alpha /{ }^{\circ}$ & $70.949(2)$ \\
\hline$\beta /{ }^{\circ}$ & $88.423(2)$ \\
\hline$\gamma /{ }^{\circ}$ & $69.662(2)$ \\
\hline$V / \AA^{3}$ & $2852.1(2)$ \\
\hline$Z$ & 2 \\
\hline Cell measurement reflections used & 9807 \\
\hline$\theta_{\min }, \theta_{\max } /^{\circ}$ & $2.24-24.66$ \\
\hline Completeness (to $\theta=24.95^{\circ}$ ) & $98.0 \%$ \\
\hline$h, k, l$ range & $-14<h<14,-18<k<18,-20<l<20$ \\
\hline Absorption coefficient $/ \mathrm{mm}^{-1}$ & 1.831 \\
\hline $\mathrm{T}_{\min }, \mathrm{T}_{\max }$ & $0.7340,0.6474$ \\
\hline $\mathrm{R}$ (merg) before/after correction & $0.0769 / 0.0500$ \\
\hline Reflections measured & 71525 \\
\hline Independent reflections & $9792[R($ int $)=0.0544]$ \\
\hline Observed reflections & 8994 \\
\hline Data / restraints / parameters & $8994 / 0 / 729$ \\
\hline Goodness-of-fit on $F^{2}$ & 1.135 \\
\hline Weighting scheme & $\begin{array}{l}\mathrm{w}=1 /\left[\sigma^{2}\left(F_{o}{ }^{2}\right)+\left(0.0377^{*} P\right)^{2}+14.8218^{*} P\right] \text { where } \\
P=\left(F_{o}{ }^{2}+2 F_{c}{ }^{2}\right) / 3\end{array}$ \\
\hline Final $R$ indices $[\mathrm{I}>\sigma(I)]$ & $R 1=0.0638, w R 2=0.1383$ \\
\hline$R$ indices (all data) & $R 1=0.0705, w R 2=0.1417$ \\
\hline Extinction coefficient & $0.0016(2)$ \\
\hline$\Delta \rho_{\max }, \Delta \rho_{\min } / \mathrm{e} \AA^{-3}$ & $0.627 ;-1.158$ \\
\hline
\end{tabular}

Bull. Chem. Soc. Ethiop. 2018, 32(3) 
<smiles>[R]C(=O)OCC(=O)OC</smiles>

(I)

(II)

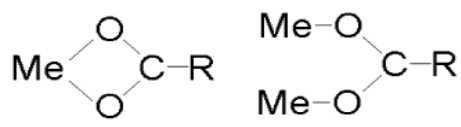

(III)

(IV)

Figure 5. Structure of metal carboxylates according to the type of metal-ligand interaction. (I) Ionic or uncoordinated form, (II) unidentate coordination, (III) bidentate chelating coordination, and (IV) bidentate bridging coordination.

Table 3. Selected IR bands $\left(\mathrm{cm}^{-1}\right)$ for the complex.

\begin{tabular}{|c|c|c|c|c|c|c|}
\hline \multicolumn{7}{|c|}{ Assignments } \\
\hline$v(\mathrm{O}-\mathrm{H})$ & $v_{\text {asy }}(\mathrm{CH})$ & $\left.v_{\text {asy }} \mathrm{COO}\right)^{\mathrm{a}}$ & $v_{\text {sy }}(\mathrm{COO})^{\mathrm{a}}$ & $\delta\left(\mathrm{CH}_{3}\right)^{\mathrm{a}}$ & $v\left(\mathrm{C}_{-}-\mathrm{CH}_{3}\right)^{\mathrm{b}}$ & $\rho_{\mathrm{r}}\left(\mathrm{CH}_{3}\right)^{\mathrm{a}, \mathrm{b}}$ \\
\hline 3520 & 2970 & 1615 & 1430 & 1375 & 1298 & 1080 \\
\hline$\pi\left(\mathrm{CH}_{3}\right)^{\mathrm{b}}$ & $v\left(\mathrm{C}^{\mathrm{C}} \mathrm{CO}_{2}\right)^{\mathrm{c}}$ & $\delta(\mathrm{OCO})^{\mathrm{a}, \mathrm{d}}$ & $\gamma(\mathrm{COO})^{\mathrm{a}, \mathrm{d}}$ & $v_{\text {asy }}\left(\mathrm{Fe}_{2} \mathrm{ZnO}\right)^{\mathrm{d}}$ & $\pi\left(\mathrm{Fe}_{2} \mathrm{ZnO}\right)^{\mathrm{c}}$ & \\
\hline 1015 & 812 & 654 & 611 & $680\left(\mathrm{~A}_{1}\right), 450\left(\mathrm{~B}_{2}\right)$ & 329 & \\
\hline
\end{tabular}

$v$ : stretching; $\delta$ : in plane bending; $\gamma$ : out of plane bending; $\rho_{\mathrm{r}}$ : rocking in plane; $\pi$ :rocking out of plane.

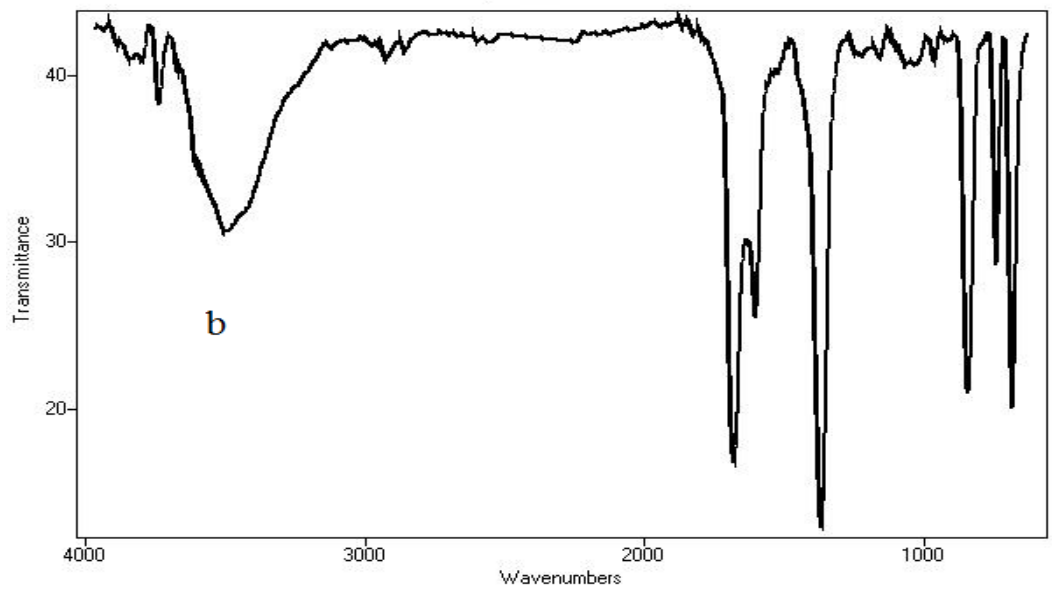

Figure 6. IR spectra of $\left[\mathrm{Fe}_{2} \mathrm{ZnO}\left(\mathrm{CHCl}_{2} \mathrm{CO}_{2}\right)_{6}\left(\mathrm{CHCl}_{2} \mathrm{CO}_{2}\right)_{3}\right] \cdot \mathrm{NO}_{3}(\mathrm{KBr}$ pellet$)$.

\section{Electronic spectroscopy}

The electronic spectrum of the trinuclear complex can be interpreted to a good approximation in terms of the individual metal ions, together with ligand-metal charge transfer transitions. The electronic spectrum of the complex was recorded in the range of 200-600 nm in dichloromethane solution. The spectrum of the oxo-centered complex shows the characteristic bands provided by both metal ions. The UV spectrum of the complex (Figure 7) exhibited a strong bands in the $213 \mathrm{~nm}$ which is related to the $\left(\mathrm{n} \rightarrow \pi^{*}\right)$ transition of the carboxylate ligand. 


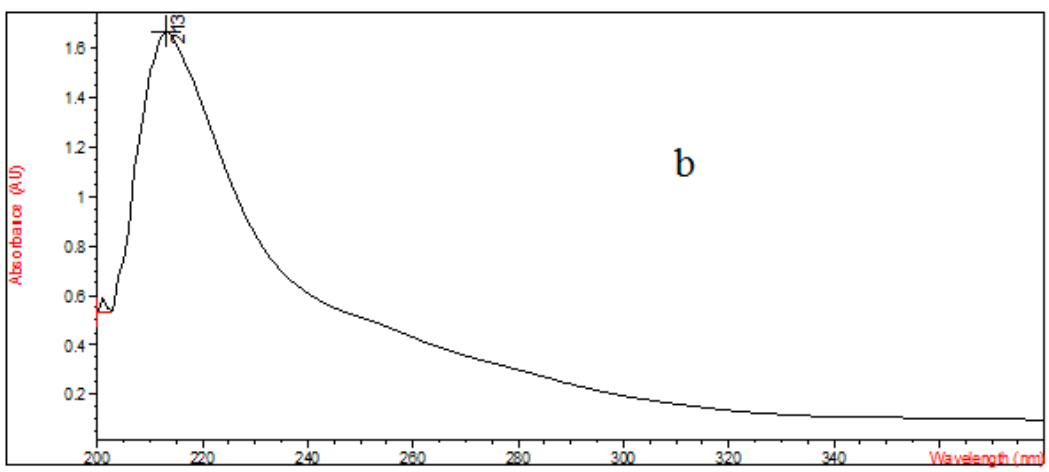

Figure 7. UV spectra of the $\left[\mathrm{Fe}_{2} \mathrm{ZnO}\left(\mathrm{CHCl}_{2} \mathrm{CO}_{2}\right)_{6}\left(\mathrm{CHCl}_{2} \mathrm{CO}_{2}\right)_{3}\right] \cdot \mathrm{NO}_{3}(\mathrm{~b})$

The Vis spectrum for this complex is shown in Figure 8. As is obvious in this Figure, broad band in the region $480 \mathrm{~nm}$, which can be assigned to the transition from Eg to $\mathrm{T}_{2} \mathrm{~g}$, should be attributed to the existence of $\mathrm{Zn}^{(\mathrm{II})}\left(\mathrm{d}^{10}\right)$ ion in these complexes. Obtained data can be assigned and characterized based on other literature [21].

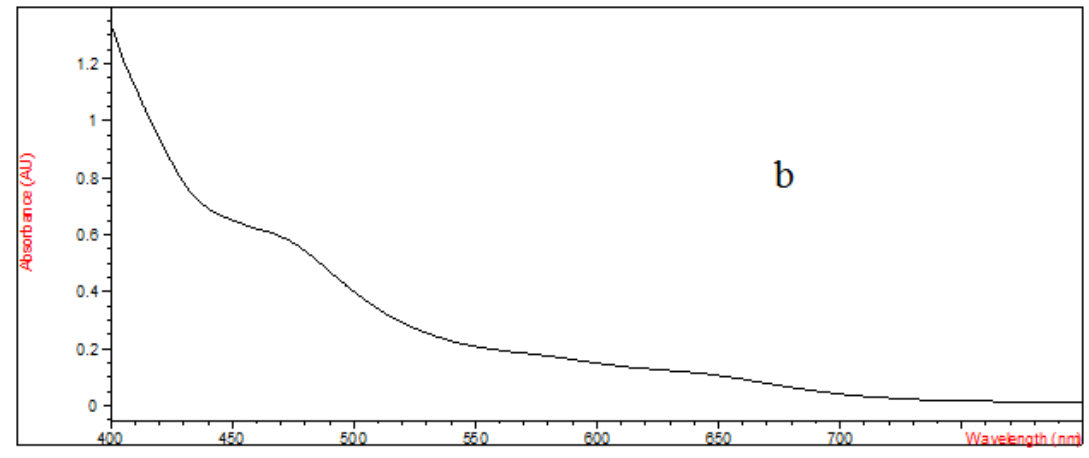

Figure 8. Vis spectra of the $\left[\mathrm{Fe}_{2} \mathrm{ZnO}\left(\mathrm{CHCl}_{2} \mathrm{CO}_{2}\right)_{6}\left(\mathrm{CHCl}_{2} \mathrm{CO}_{2}\right)_{3}\right] . \mathrm{NO}_{3}$.

\section{CONCLUSION}

The new oxo-centered trinuclear complex with the general formula $\left[\mathrm{M}_{2} \mathrm{M} \mathrm{O}\left(\mathrm{CHCl}_{2} \mathrm{COO}\right)_{6}(\mathrm{~L})_{3}\right]$ where $\mathrm{M}=\mathrm{Fe}, \mathrm{M}^{\prime}=\mathrm{Zn}, \mathrm{L}=\mathrm{CHCl}_{2} \mathrm{CO}_{2}$ (2) were prepared and studied by elemental analysis $(\mathrm{CHN})$, electronic and infrared spectroscopy and atomic absorption spectroscopy. The compound has a similar $\mu_{3}$-oxo structure. The IR investigations of these compounds show intensive absorption bands, which are assigned to $v_{\text {asym }}(\mathrm{COO})$ and $v_{\text {sym }}(\mathrm{COO})$ vibrations. Furthermore, the three metal ions are bound to a central oxygen atom and adjacent metal ions are bridged by two carboxylate ligands. In addition, for mixed metal complex, the atomic absorption data show a statistical 2:1 disorder of iron and manganese atoms, respectively.

\section{ACKNOWLEDGEMENTS}

The authors gratefully acknowledge the Qeshm Branch, Islamic Azad University, for financial support of this project. 


\section{REFERENCES}

1. Kim, J.; Cho, H. Reductive coupling of trinuclear $\left[\mathrm{Mn}^{\mathrm{II}} \mathrm{Mn}^{\mathrm{III}}{ }_{2} \mathrm{O}\right]$ core to form hexanuclear $\left[\mathrm{Mn}_{4}{ }^{\mathrm{II}} \mathrm{Mn}_{2}{ }^{\mathrm{III}} \mathrm{O}_{2}\right.$ ] cluster. Inorg. Chem. Commun. 2004, 7, 122-124.

2. Beattie, J.K.; Klepetko, J.A.; Masters, A.F.; Turner, P. The chemistry of cobalt acetate. VIII. New members of the family of oxo-centred trimers, $\left[\mathrm{Co}_{3}\left(\mu_{3}-\mathrm{O}\right)\left(\mu-\mathrm{O}_{2} \mathrm{CCH}_{3}\right)_{5-p}(\mu-\mathrm{OR})_{p} \mathrm{~L}_{5}\right]^{2+}$ $(\mathrm{R}=\mathrm{H}$, alkyl, $\mathrm{L}=$ ligand, $\mathrm{p}=0-4)$. The preparation and characterisation of the trimeric tetrakis( $\mu$-acetato)-( $\mu$-hydroxo)- $\mu_{3}$-oxo-pentakis(pyridine)-tri-cobalt(III) hexafluorophosphate, $\left[\mathrm{Co}_{3}\left(\mu_{3}-\mathrm{O}\right)\left(\mu-\mathrm{O}_{2} \mathrm{CCH}_{3}\right)_{4}(\mu-\mathrm{OH})\left(\mathrm{C}_{5} \mathrm{H}_{5} \mathrm{~N}\right)_{5}\right]\left[\mathrm{PF}_{6}\right]_{2}$. Polyhedron 2003, 22, 947-965.

3. Gavrilenko, K.S.; Vertes, A.; Vanko, G.; Kiss, L.F.; Addison, A.W.; Weyhermuller, T.; Pavlishchuk, V.V. Synthesis, magnetochemistry, and spectroscopy of heterometallic trinuclear basic trifluoroacetates $\left[\mathrm{Fe}_{2} \mathrm{M}\left(\mu_{3}-\mathrm{O}\right)\left(\mathrm{CF}_{3} \mathrm{COO}\right)_{6}\left(\mathrm{H}_{2} \mathrm{O}\right)_{3}\right] \cdot \mathrm{H}_{2} \mathrm{O}(\mathrm{M}=\mathrm{Mn}, \mathrm{Co}, \mathrm{Ni})$. Eur. J. Inorg. Chem. 2002, 2002, 3347-3355.

4. Blake, A.B.; Sinn, E.; Yavari, A.; Murray, K.S.; Moubaraki, B. Preparation and crystal structure analysis of a novel oxo-centered mixed-metal complex containing bridging carboxylates ligands. J. Chem. Soc. Dalton Trans. 1998, 45, 158-166.

5. Wu, R.; Poyraz, M.; Sowrey, F.E.; Anson, C.E.; Wocadlo, S.; Powell, A.K.; Jayasooriya, U.A.; Cannon, R.D.; Nakamoto, T.; Katada, M.; Sano, H. Electron localization and delocalization in mixed-valence transition metal clusters: structural and spectroscopic studies of oxo-centered trinuclear complexes $\left[\mathrm{Fe}_{3} \mathrm{O}\left(\mathrm{OOCCMe}_{3}\right)_{6}(\mathrm{py})_{3}\right]$ and $\left[\mathrm{Mn}_{3} \mathrm{O}(\mathrm{OOCCMe})_{6}(\text { py })_{3}\right]$. Inorg. Chem. 1998, 37, 1913-1921.

6. Chavan, S.A.; Srinavas, D.; Ratnasamy, J.A novel, zeolite-encapsulated $\mu_{3}$-oxo Co/Mn cluster catalyst for oxidation of para-xylene to terephthalic acid. Chem. Commun. 2001, 12, 1124-1130.

7. Maragh, P.T.; Thomas, S.E.; Dasgupta, T.P. Kinetics and mechanism of the aquation of the trinuclear cation, $\left[\mu_{3} \text {-oxo-triaqua-hexakis(acetato)tris (iron(III)) }\right]^{+}$in perchloric acid media. Inorg. Chim. Acta 2005, 358, 3610-3616.

8. Yazdanbakhsh, M.; Lotfian, N.; Tavakkoli, H. Synthesis and characterization of two novel trinuclear oxo-centered, of chromium and iron complexes containing unsaturated carboxylate bridging ligand. Bull. Chem. Soc. Ethiop. 2009, 23, 463-466.

9. Woehler, S.E.; Wittebort, R.J.; Oh, S.M.; Hendrickson, D.N.; Inniss, D.; Strouse, C.E. Solidstate deuterium NMR, iron-57 Moessbauer, and X-ray structural characteristics of $\mu$-3-oxobridged mixed-valence $\left[\mathrm{Fe}_{3} \mathrm{O}\left(\mathrm{O}_{2} \mathrm{CCH} 3\right)_{6}(4-\mathrm{Me}-\mathrm{py})_{3}\right]\left(\mathrm{C}_{6} \mathrm{H}_{6}\right)$ : dynamics of the benzene solvate molecules influencing intramolecular electron transfer. J. Am. Chem. Soc. 1986, 108, 2938-2946.

10. Yazdanbakhsh, M.; Tavakkoli, H.; Taherzadeh, M.; Boese, R. Synthesis, X-ray crystal structure and spectroscopic characterization of heterotrinuclear oxo-centered complex $\left[\mathrm{Fe}_{2} \mathrm{NiO}\left(\mathrm{CH}_{3} \mathrm{CH}_{2} \mathrm{COO}\right)_{6}\left(\mathrm{H}_{2} \mathrm{O}\right)_{3}\right]$. J. Mol. Struct. 2010, 982, 176-180.

11. Tavakkoli, H.; Yazdanbakhsh, M.; Lotfian, N.; Boese, R. Synthesis, characterization and crystal structure analysis of a novel oxo-centered mixed-metal complex containing unsaturated bridging carboxylates. Cent Eur J Chem. 2011, 9, 585-589.

12. Yazdanbakhsh, M.; Khosravi, I.; Tavakkoli, H. Synthesis and characterization of novel oxobridged, trinuclear mixed-metal complexes of $\mathrm{Cr}(\mathrm{III})$ and Fe(III). J. Serb. Chem. Soc. 2009, 74, 401-406.

13. Yazdanbakhsh, M., Alizadeh, M.H.; Khorramdel, H.Z.; Frank, W. Synthesis, characterization and crystal structure of novel mixed bridged trinuclear oxo-centered iron(III), chromium (III) complexes containing terminal unsaturated carboxylato and acrylic acid dimer anion ligands. Anorg. Z. Allg. Chem. 2007, 633, 1193-1198.

14. Ghaemi, A.; Tavakkoli, H.; Khosravi, I. Preparation, spectral and thermal characterization of two novel mixed-valent and metal trinuclear oxo-centered complexes. Asian J. Chem. 2012, 24, 3177-3180. 
15. Sheldrick, G.M. SHELXTL v 6.12, Structure Determination Software Suit. Bruker AXS: Madison; 1998.

16. Shova, S.; Prodius, D.; Mereacre, V.; Simonov, Y.A.; Lipkowski, J.; Turta, C. Discernible apical coordination in $\mu_{3}$-oxo-bridged mixed metal trinuclear carboxylate $\left[\mathrm{Fe}_{2} \mathrm{MnO}\left(\mathrm{CHC}_{12} \mathrm{COO}\right)_{6}(\mathrm{THF}) 2 \mathrm{H}_{2} \mathrm{O}\right]$. Inorg. Chem. Commun. 2004, 7, 292-295.

17. Baranwal, B.P.; Fatma, T.; Varma, A. Synthesis, spectral and thermal characterization of nano-sized, oxo-centered, trinuclear carboxylate-bridged chromium(III) complexes of hydroxycarboxylic acids. J. Mol. Struct. 2009, 920, 472-477.

18. Zhang, K.L.; Shi, Y.J.; You, X.Z.; Yu, K.B. Preparation, crystal structure and characterization of a novel iron(III) oxide cluster containing two different discrete $\left[\mathrm{Fe}_{3} \mathrm{O}\right]$ units. J. Mol. Struct. 2005, 743, 73-77.

19. Boudalis, A.K.; Lalioti, N.; Spyroulias, G.A.; Raptopoulou, C.P.; Terzis, A. Novel rectangular $\left[\mathrm{Fe}_{4}\left(\mu_{4}-\mathrm{OHO}\right)(\mu-\mathrm{OH})_{2}\right]^{7+}$ versus "butterfly" $\left[\mathrm{Fe}_{4}(\mu 3-\mathrm{O}) 2\right]^{8+}$ core topology in the FeIII/ $\mathrm{RCO}_{2}$-/phen reaction systems $(\mathrm{R}=\mathrm{Me}, \mathrm{Ph}$; phen $=1,10$-Phenanthroline $)$ : Preparation and properties of $\left[\mathrm{Fe}_{4}(\mathrm{OHO})(\mathrm{OH})_{2}\left(\mathrm{O}_{2} \mathrm{CMe}\right)_{4}(\text { phen })_{4}\right]\left(\mathrm{ClO}_{4}\right)_{3},\left[\mathrm{Fe}_{4} \mathrm{O}_{2}\left(\mathrm{O}_{2} \mathrm{CPh}\right)_{7}(\text { phen })_{2}\right]\left(\mathrm{ClO}_{4}\right)$ and $\left.\left[\mathrm{Fe} 4 \mathrm{O}_{2}\left(\mathrm{O}_{2} \mathrm{CPh}\right)_{8} \text { (phen }\right)_{2}\right]$. Inorg. Chem. 2002, 41, 6474-6487.

20. Cannon, R.D.; White, R.P. Progress in Inorganic Chemistry, Vol. 36, Wiley: New York; 1998; p 23.

21. Mizoguchi, T.J.; Davydov, R.M.; Lippard, S.J. Structural and spectroscopic comparisons between ( $\mu$-oxo)- and ( $\mu$-hydroxo)bis( $\mu$-carboxylato) diiron(III) complexes that contain all-oxygen-donor ligands. Inorg. Chem. 1999, 38, 4098-4103. 